filaria, for any use vhatever. It is a common belief amongst many of the natives that with regari to water all that they have to do is to procure a sweet supply of water for drinking purposes alone. Regarding water for cooking, bathing, and other works, they are indifferent. Once they meet with a water sweet in taste and all is done for them. No consideration for its source, smell, dirt and the surrounding hygienic or unhygienic conditions, and thus here lies the whole mischief. Owing to this cause alone not only guinea-worms are not prevented, but several other contagious diseases are unavoidably produced. Therefore it should be a rule with everybody that he takes great care in selecting a pure healthy supply of water not ouly for drinking purposes alone, but also for cooking, bathing, and other household works.

When once the disease has made its appearance, the following is the mode of treatment generally adopted.

Where the worm is superficially like a ridge it is removed there and then. The part all along the ridge is to be kept covered with a piece of wet cloth dipped in simple cold water for about ten minutes, when, after removing the cloth, we shall see that the ridge becomes more marked than before. Now with a sharp scalpel about three-quarters of an inch long incision along the line of the ridge and a little to one side of it and not just over it, should be carefully made so as not to injure the worm. Afterwards the skin and the fæcia with the other superficial parts should be dissected out on each side of the worm which now becomes quite visible. Then a strong long needle should be introduced underneath the parasite and the pointing end of the needle taken out the other side. Now the needle with the parasite on must be drawn upwards, and finally the worm seized with the fingers, and by gradual but gentle pulling up and friction of the surrounding parts it is removed whole and entire. Sornetimes it is found to enlarge the incision to more than two inches in length. The length of the parasite is generally more than 24 inches.

Where sacculated abscesses are formed these are opened. The cavities should be thoroughly cleaned out with some antiseptic lotion such as carbolic, boric or sublimate.

No special mode of treatment is necessary in such sases, and in due time the wounds are healed up.

It is in broken cases of guinea-worms with unbearable troubles that active treatment is called for. Here the skill of the surgeon or the intellect of the physician is of essential importance. In India innumerable drugs have been tried with no satisfactory results. Suffice it to say that the proverb "eka naru bazar daru" (thousand medicines for one guinea-worm) has been well-known to the natives of this country from time immemorial. Indeed, the sufferings of a patient attacked with broken guinen-worms are great, and it has been earnestly expected that a sovereign remedy should come to light one day or other for ameliorating the condition of such sick-poor.

In my last letter I advocated the use of the bruised leaves of "Omarpatee," the description of which was also stated. Here I have only to add that my further experience of the leaves has served to confirm my views already stated; others may give a fair trial to the leaves and record their experiences.

I place the above few words on record in order to obtain correct theories as regards the cause of the disease and the proper treatment for the cases of broken guinea-worms.

BARNAGAR, C. I.; May 1894.

\section{B. VINZE,}

Hispital Assistant.

\section{"VESTIGIA NULLA RETRORSUM."}

To the Editor, "Indian Medical Gazette."

DEAR SIR, - It is not a little disheartening to workers in scientific medicine to read an artisle like that in the editorial columns of the Pioneer of June 1st on the subject of enteric fever and its causation.

The Pioneer is presumably the organ of lay opinion on topics such as these, and the public are perhaps only too ready to allow their ideas on this and kindred subjects to be shaped for them by the newspaper to which they resort for their stock of daily information. So that when this information is based on incomplete knowledge an unfortunate perversion of public opinion is apt to be the result.

'This is doubly lamentable in the present instance, inasmuch as the Pioneer has the reputation of being officially inspired, and it may be that the thinking section of the public will run away with the idea that the views put forward in the editorial to which $I$ shall refer at some length, are representative of the state of scientific knowledge in India. This is the more to be feared as few of those outside the profession who take any thought for this and kindred subjects have any access to papers in which more accurate information is to be had, and the consequence is that a distorted and dangerous view of these questions is the only one available to the general public, and yet an accurate, not to say a somewhat intimate, acquain tance with the real facts is of the utmost importance to the European community in India, more especially with reference to the causation and prevention of typhoid fever, as it is to the public alone we can look for any such cogent expression of opinion as shall result in the adoption of efficient measures for the check of typhoid in India.

The conclusion at which the Pioneer arrives, from its very insufficient premisses, is in its own words, as follows:-"One affirmation meanwhile admits of being made with certainty, that the disease chiefly falls on young men and new arrivals to the country. Taking this fact as a basis, does it not lead to the conclusion that the origin of the fever is to be found in climatic causes, rather than in a specific poison taken into the system from insanitary surroundings-a liability which no improvements in sanitation seem to have any tendency to reduce." If the Pioneer means by this that the fact that the incidence of typhoid fever is mainly on young men is any evidence of the "climatic" origin of typhoid, then we may apply this reasoning equally to the climates of England, Russia, Denmark, America, and arrive at the very satisfactory (?) conclusion that the "climate," whatever that climate may be, is the source of typhoid. A truly lame conclusion.

We do not, however. think for one moment that this is the real belief of the Pioneer, but we believe that the key to its position is to be found in the last sentence of the above-quoted paragraph, viz., "a liability whic h no improvements in sanitation seem to have any tendency to reduce," a statement of which the whole article is an expansion. The argument then is this-(1) Sanitary improvements on an enormous scale have been carried out in the towns and cantonments of Upper India during the last decade. (2) We have an increase, or at any rate no decrease, in this " frightfully prevalent disease " in spite of these enormous sanitary improvements. (3) Therefore, sanitary improvements have no tendency to reduce the liability to typhoid fever.

This argument may, at first sight, seem sound, and it is this very appearance of soundness in the reasoning which makes the editorial in which it occurs an element of danger, inasmuch as the logical outcome of it would be to abandon all attempts at sanitary improvements directed to check the prevalence of typhoid fever. It will be my object to draw attention to the dangerous fallacy underlying this argument.

The conclusion arrived at is bolstered up by a reference to the multifarious channels by which the typhoid germ is asserted to gain access to the human body with a somewhat supercilious reference to "scientific ingenuity" which in one year impugns the dairy, or if not the dairy, the "foul well in which the native dairyman washed the utensils, and from which he probably watered the milk if he get a chance," or, finally, as in the present outbreak, the "cream or curds which the khansamahs got in the bazar."

I am fully wrepared to grant the general conclusion arrived at which is this: "If you have a dozen sources of approach and shut all of them but one, and that the smallest, nay, if the veriest chink be left open, the enemy will still enter as freely and be as destructive as when the ingress was unrestricted." It is not only in accord with the doctrine of probabilities, it is an incontrovertible fact, and so far from its being a reductio ad absurdum as the editorial asserts, it is a deductio rationis.

Were we talking of organisms whose power for ill depended solely upon the number gaining admission originally there might be some excuse for this allegation of absurdity, but if we realise the fact that one solitary bacillus falling upon a favourable soil will eventually, and that in an incredibly short time, produce millions of its kind, it becomes evident that short of the absolute exclusion of the individual bacillus we cannot have safety, and if we cannot extend our defensive operations to the closure of this 
"veriest chink," we must assume the offensive and endeavour to destroy the enemy before he can enter. How lamentably inadequate our efforts in this direction are we shall presently show.

The article goes on triumphantly to discomfit the sanitarians by an attempted comparison between typhoid and cholera. "Improve the water-supply of a cholera-stricken locality, and it has been proved a hundred times pre-eminently, for example, in Calcutta that you will have an immediate fall in the death-rate. But instead of new dairies and water-supply arrangements producing a like effect in the reduction of typhoid, we see regiments obliged to go out into camp in the hope of shaking off the infection as if they were haunted by cholera, while in some stations the young officer or soldier may count an attack of enteric as almost as likely to befall him as the measles in childhood." The italics are mine. This is strong writing, and will, no doubt, attract attention of parents in England, more especially after the recent lamentable losses by the East Surrey Regiment in Agra. It is also unfortunately true in a measure.

The comparison, however, seems to be intended to tell against sanitation as a means of prevention of typhoid, an herein lies the whole fallacy of the argument. Now to examine the terms of the syllogism we find the first is this : "Enormous sanitary improvements have been carried out in the towns and cantonments of Upper India during the last decade."

This premiss is true, but only partially $80:$ it is true as regards sanitary reforms in general, it is not true as regards enteric fever prevention.

Nay more, I believe, that it is quite possible that those very measures of sanitation have much to answer for in spread. ing enteric ferer in India.

If this be so, then the state of the case would be better represented as follows :-

1. Enormous "sanitary" measures have been carried out in the towns and cantonments of Upper India during the last decade.

2. Sanitary measures of approved efficacy reduce the tendency to the spread of typhoid.

3 . Therefore, in view of the fact that there is no decrease in this frightfully prevalent disease-typhoid, our "enormous sanitary" measures are not sanitary measures of approved efficacy.

It remains, therefore, to reconsider our position with regard to our "sanitary improvements" in connection with typhoid. These fall naturally under two heads :-

(a) Securing a good and pure food-supply.-This will include the preservation of water and all other food-stuffs from contamination by the "typhoid" germs.

(b) Destruction of the contaminating agency.-This will include the disposal of excreta and other sources of infection emanating from the subjects of typhoid: and also the disposal of the bodies of those who have succumbed to the disease.

We must now ask ourselves: Are the measures we adopt efficacious in securing the end we have in view ?

'The answer to this question, so far as regaris the purity of food-supply, may fairly be answered in the affirmative; in most places all possible precautions are being taken to ensure the purity of the water-supply and the preservation of dairy produce from contamination. When, however, we come to examine the position of affairs with reference to the destruction of the contaminating agency the case is very different, and we are forced to conclude that there is vast room for improvement, which in the interests of the living are of urgent importance.

1. How do we dispose of excreta, \&c., of the sick ?

We bury them, after more or less imperfect disinfection, in the earth, in deep or shallow trenches, or in some cases an inch or two below the surface of the ground, and we go away and flatter ourselves that having put them out of sight and (where the utmost care is taken) destroyed the disagreeable effluvia, we have secured our community against infection by typhoid.

2. How do we dispose of our dead?

By burial in closed cases which after a longer or shorter time leak and allow the contents to percolate into the soil, to be brought to the surface after a longer or shorter period.

Now, so far as sanitation in these respects goes, to the general, excreta are excreta, and one dead body is much the same as another.
But this is a most dangerous conclusion as regards typhoid for the reason that the typhoid germ possesses a very high degree of vitality, and more especially in the soil they may continue to live indefinitely, undergoing rapid and conti. nuous multiplication, so that the disposal of imperfectly disinfected typhoid excreta by burial in or upon the earth, is virtually to convert that plot of earth into a nurserygarden for typhoid bacilli.

The same may be said (only perhaps the danger is somewhat more deferred) of the burial of persons dead from typhoid in the ground without any antiseptic precautions whatever as obtains at present. I have said the danger is more deferred, but it is none the less real. It may be defer. red because of the enclosure of the corpse in the coffin, and its burial at a greater depth, but it is none the less real as the bacilli will sooner or later become free in the soil, and play their part in contaminating water-supply and air.

The researches of Uffelmann* Karlinski, Grancher and others shew conclusively how real a danger this is. It is no bogie to frighten timid women and children, nor is it a Ducdame to cull sauit:uri:un fools into a circle. It is a solid tangible danger with which we have to reckon.

Uffelmann's most recent experiments shewed that typhoid bacilii resist drying and retain their power of development (1) in garden earth 21 days ; (2) in white filter sand 82 days ; (3) in sweepings from house and street over 30 days; (4) on linen 60 to 72 days; (5) on buckskin 80 to 85 days; and (6) on wood 32 days. In a moister atmosphere the duration of life is even longer. Grancher and Deschamps found typhoid germs are capable of reproducing themselves after five and-a-half months in moist ground.

Uffelmaun's experiments also prove that typhoid bacilli are carried into the air with dust, and thus are enabled to infect milk or other food-stuffs.

In the light of the above it will perhaps now be seen why that "veriest chink" is of such vital importance; so long as we allow the contamination of the soil to go on as at present, we cannot keep the air even moderately free from typhoid germs, and where there is a "chink" to admit that air there typhoid germs will go if they be pre sent in the air.

The fallacy in comparing cholera with typhoid to which I have alluded above is this: The cholera germ is very speedily killed by drying, whereas the typhoid germ resists arying. 'The presence of moisture to some extent prevents the diffusion of germs in the air by air currents, but when dryness prevails the dust laden with typhoid germs can effectually infect water, milk, \&c. In this way measures which are effectual with the one germ are of no efficacy as against the uther : hence the parallel attempted to be drawn falls to the ground.

Finally, if we are to check the spread of typhoid, we must not rest contented with blocking the avenues of approach, we must strike at the root of the mischief, and this can only be done by the thorough destruction of the typhoid germs. We must destroy them " wherever we may find them "-if in the excreta, by thorough disinfection after the most approved methods; the mere admixture of a few ounces of perculoride solution, too often perfunctorily performed, is not enough. No typhoid excreta should be allowed to be disposed of till they have been disinfected with perchloride at steam heat for a sufficient time. No corpse of a typhoid patient should be committed to the ground unless with rigid antiseptic precautions; it is too much to hope for cremation of such bodies being made compulsory, but this is the direction in which I personally would advocate precau. tionary measures, believing as I do that this, and this alone, is the rational mode of disposing of infectious dead bodies.

It is high time for some such measures to be adopted to vindicate the claims of medical science and save Europeans in India from the disaster which must inevitably befall them if "climatic causes" are to be accepted as the origin of enteric fever. India cannot afford to have this new stigma cast upon her scientists, who have too of ten been in the rear while the battle is fought elsewhere, - "nulla re. trorsum" must now be her motto.

\section{GEORGE RANKING, M.D.}

* Note.-Since writing this letter I have seen the report of Dr. Dempster's work in this connection, which goes to shew a still higher degree of vitality for the typhoid germ. 